\title{
Media Representations of Lesbians, Gay Men, and Bisexuals on Dutch Television and People's Stereotypes and Attitudes About LGBs
}

\section{Megan May van Meer ${ }^{1} \cdot$ Monique Maria Henriette Pollmann ${ }^{1}$ (D)}

Accepted: 8 September 2021 / Published online: 22 September 2021

(c) The Author(s) 2021

\begin{abstract}
This study investigates stereotypical portrayals of lesbians, gays, and bisexuals (LGBs) on Dutch television and whether these portrayals relate to people's attitudes towards LGBs. Previous research shows that television programs in the U.S. contain many stereotypical portrayals of LGBs. These portrayals are both negatively and positively related to people's attitude towards LGBs. Because the Dutch culture is relatively accepting of LGBs it is interesting to see if they are portrayed differently than in the U.S. A content analysis showed that there are stereotypical representations on Dutch television but there are also people who 'just happen to be gay'. A survey among 272 participants showed that people who more frequently watch programs with stereotypical portrayals of LGBs do not have a more positive or negative attitude than people who do not. A mediation analysis showed that people who watch more television in general have a more stereotypical view of gay men, which is related to more negative attitudes towards LGBs.
\end{abstract}

Keywords Stereotypes $\cdot$ Media $\cdot$ Homosexuality $\cdot$ Television $\cdot$ Media representation $\cdot$ Content analysis

\section{Introduction}

There are many stereotypes about homosexuality that gay men and lesbians are confronted with in their daily life and the media play an important role in forming these stereotypes. Cultivation theory states that repeated exposure to a system of messages can influence people's attitudes and views of reality. Media especially influence our view on subjects that we have little experience with (Morgan et al., 2009). Adolescents, for example, indicate the media as their top source of sexual information

Monique Maria Henriette Pollmann

m.m.h.pollmann@uvt.nl; m.m.h.pollmann@tilburguniversity.edu

1 Department of Communication and Cognition, Tilburg University, PO Box 90153, 5000 LE Tilburg, The Netherlands 
(Brown et al., 2005). Controversial topics like homosexuality may cause shame and discomfort when discussed with peers or parents. This provides reason to believe that people gain information and create attitudes about homosexuality through the media (Calzo \& Ward, 2009).

Repeated media exposure makes certain characteristics more available in our memory and hereby create stereotypes. These stereotypes subsequently shape our attitudes and view of reality (Morgan et al., 2009). Most stereotypes about lesbians are about them having masculine characteristics and most stereotypes about gay men are about them having feminine characteristics (Blashill \& Powlishta, 2009a). Because these stereotypes defy gender norms (women are supposed to be feminine and men are supposed to be masculine) they can cause negative attitudes towards LGBs (Blashill \& Powlishta, 2009b). In the current study, we will investigate whether the Dutch media landscape can be linked to attitudes Dutch people have about LGBs. The Netherlands are especially interesting to study because Dutch people have the most positive attitude towards lesbians, gays, and bisexuals (LGBs) of the whole EU (Gerhards, 2010). It may be that the Dutch media landscape is less stereotypical and therefore the Dutch hold more positive attitudes. Here, we present a content analysis of programs that are on Dutch television and a survey on the link between exposure to these programs and people's attitudes towards and views of LGBs.

\section{Stereotypes of LGBs}

Stereotypes in itself are not necessarily bad. Stereotypes help us navigate the world, as they allow us to use information about a category to make sense of individual things. For example, if I see an animal, it helps to know that it belongs to the category cats and based on what is stereotypical for cats (purrs if satisfied, arches back if angry) I can interpret its mood state. However, when stereotypes are used in social interactions, it can lead to prejudice. Not all individuals fit the stereotype and one should not judge an individual human being based on stereotypes one holds about their group, but should get to know them personally. In this paper, we use the term 'stereotypes' and 'stereotypical representations' to describe the shared ideas people have about LGBs. We do not investigate prejudice nor do we want to imply that stereotypes are always negative. We are interested in whether stereotypical representations can be found in the media and how they relate to people's attitudes.

What kind of stereotypes are there about LGBs? Multiple studies confirm that people generally ascribe feminine characteristics, such as empathy, nurturance, and sensitivity, to gay men and masculine characteristics, such as autonomy, dominance, and assertiveness to lesbians (Blashill \& Powlishta, 2009a; Eliason et al., 1992; Kite \& Deaux, 1987; Madon, 1997). People attribute feminine characteristics (from the Occupations, Activities, and Traits-Attitudes Measure (OAT-AM, short version, Liben \& Bigler, 2002)) more to gay men than to heterosexual men and lesbians and equally to gay men and heterosexual women. Also, people attribute masculine characteristics more to lesbians than to heterosexual women and homosexual men (Blashill \& Powlishta, 2009a). 
Gender-related stereotypes about LGBs also prevail in The Netherlands. A survey about stereotypes and homophobia among 339 Dutch adolescents between the age of 13 and 19 years old (Dankmeijer \& Schouten, 2013) shows that more than $60 \%$ of the characteristics ascribed to gay men and lesbians were gender-related, gay men were typically described as feminine, lesbians were typically described as masculine.

\section{Stereotypes of LGBs on Television}

How are LGBs represented on television and are these portrayals stereotypical? To our knowledge, there are no studies that analyzed how LGBs are represented on Dutch television. But there is one study that analyzed if LGB are represented. This content analysis of 503 fictional programs on Dutch television between 1980 and 2005 showed that only $3.8 \%$ of the 2104 analyzed characters were LGBs (Emons et al., 2010). This means that LGBs are underrepresented on Dutch television, as $13 \%$ of the Dutch population identifies either as gay, lesbian, or bisexual (Keuzenkamp et al., 2012).

U.S. studies have shown that LGB characters on U.S. television are most likely to be white homosexual men between the age of 20 and 35 years (Fouts \& Inch, 2005). There are two main types of gay men on television: either the non-threatening representation of a heteronormative, non-sexual, rich white man with a successful career (like Will from Will and Grace or Mitch from Modern Family) or the flamboyant, stereotypical and overdramatic gay man (like Jack from Will and Grace or Cameron from Modern Family) (Rothmann, 2013). In general, LGBs are rarely displayed in a sexual context on television (Fisher et al., 2007; Hart, 2000). An LGB character is more likely to be seen holding hands or giving a hug than to be engaged in an encounter where sex is implied. Furthermore, LGBs are often the subject of gaythemed jokes (Raley \& Lucas, 2006). Although some stereotypes about LGBs have faded (like LGBs are sexual predators and child molesters) other stereotypes remain, such as the flamboyant and feminine gay man. In general, how gay men are presented on television rarely covers the full range of life choices and is often restricted to being the funny character and either being unsuccessful in finding love or being promiscuous (Hart, 2000).

The findings about lesbians are similar to the findings about gay men: lesbians are represented in a heterosexualized way. They are attractive and feminine and, according to Diamond (2005), are merely there to pleasure heterosexual male viewers (Diamond, 2005; Jenkins, 2005). Other studies also found that lesbians are mostly portrayed as feminine looking (Ciasullo, 2001; Farr \& Degroult, 2008; Parker et al., 2020) and as engaging more often in sexual behavior than gay men (Ramirez, 2020). There are some television programs with lesbian characters that are developed especially for lesbian and bisexual women in which the characters show more masculine characteristics (for example in their jobs and behavior) but their looks are still feminine. An explanation for this phenomenon is that the characters show masculine characteristics so they are recognized by lesbian and bisexual viewers but have 
feminine looks to make them less controversial and more acceptable for heterosexual viewers (Farr \& Degroult, 2008).

On U.S. television, bisexual characters are most likely to be female and to have a non-Caucasian ethnicity (Meyer, 2010). It is harder to identify bisexual characters on television because bisexual characters usually do not have a typical coming out narrative as gay men and lesbians do. Therefore it is only clear that they are bisexual when they have an encounter with someone of the same gender (Meyer, 2010). In some series, it sometimes takes several seasons before viewers are aware of the bisexuality of a character. Bisexual characters are usually shown in an identity crisis, where they are promiscuous and have sexual encounters with both genders. Hereby, they create an unstable image of bisexuals. Bisexual women are, just like lesbians, represented in a feminine way conforming to cultural beauty standards (Meyer, 2010). They are sexualized and seem to be there to please male heterosexual viewers (Johnson, 2016). Bisexual men are almost invisible on television, supporting the misconception that female sexuality is more fluid and male sexuality is rigid (Johnson, 2016).

LGBs in multiple studies pointed out that a richer representation of LGBs in the media is missing (Gomillion \& Giuliano, 2011; Sanz López, 2017). Participants stated they would just like to see: "normal people with normal jobs who just happen to be gay" (Gomillion \& Giuliano, 2011, p. 337). These results stress the importance of (research about) representation of LGBs in the media.

Our first goal is therefore to answer the question: Which stereotypical representations of LGBs are present on Dutch television?

\section{Cultivation Theory}

The next goal is to see how these stereotypical representations are related to people's views towards LGBs. Cultivation theory explains that exposure to a repeated system of messages (the media) can influence how people view the world (Morgan et al., 2009). Classic cultivation studies found evidence for this effect for many subjects such as crime, politics, health, and sexual behavior. For example, people who watch crime-related television programs are more afraid of crime in real life because they think crimes occur more often than they do in reality (Van den Bulck, 2004). Currently, cultivation research focuses more on the effect of specific genres (Morgan et al., 2009), because the increase in channels and the rise of streaming services cause for a less homogenous media landscape. Therefore our survey study will not only test whether television viewing as a whole is related to attitudes about LGBs but will also test the specific effect of viewing programs with high and low levels of stereotypical representations of LGBs. Based on the idea that people who watch more television hold a view of the world that is shaped by what is shown on television, we predict the following:

H1: People who view more programs with stereotypical portrayals of LGBs on television have a more stereotypical view of LGBs in reality. 
Finally, we want to test the association between media exposure and attitudes about LGBs. There are a few studies that investigated the connection between general media use and acceptance and attitudes towards homosexuality. The largest study on this, with more than 5000 participants reported a small effect showing that people who consider television their primary form of entertainment have more positive attitudes about same-sex marriage (Lee \& Hicks, 2011). This link between media exposure and positive attitudes was also found in a Chinese sample of university students (who generally held accepting attitudes towards homosexuality) (Lin et al., 2016). Calzo and Ward (2009) did not find a uniform correlation between media use and attitude towards homosexuality, the effects differed across media genres, gender, and religion. Media use was negatively related to attitudes for people with a relatively more positive attitude (people who were non-religious and female) and the effect was positive for people with a relatively more negative attitude (people who were religious and male). In experimental studies it has been found that exposure to positive portrayals of a gay person leads to more positive attitudes about homosexuals (Bonds-Raacke et al., 2007, Riggle et al. 1996).

H2: People who view more programs with stereotypical representations of LGBs on Dutch television, have more positive attitudes towards LGBs.

To investigate the research question and the two hypotheses we conducted two studies. The first study was a content analysis that investigated how LGB's are represented on Dutch television (which includes mainly productions from the U.S. and The Netherlands). The second study was a survey to investigate how these media representations are related to stereotypes and attitudes.

\section{Study 1}

\section{Method}

\section{Pilot Study}

The programs for the content analysis were selected with a pilot study in June 2017. In this study, a convenience sample of 15 participants ( 3 male, 12 female, mean age $34.07, \mathrm{SD}=14.56$ ) was asked to list as many programs on Dutch television, including streaming services such as Netflix, with LGB characters or people as they knew. The pilot study ran until no new answers were given. We did not impose any restrictions regarding the genre or the production site, therefore the selection contained Dutch as well as non-Dutch programs and programs with real-life persons as well as programs with fictional characters. With this procedure, we made sure that the sample is a good representation of programs that Dutch people know include an LGB person or character. 


\section{Sample}

From the list of programs generated in the pilot study all programs that were mentioned more than once and that were broadcasted in the last three years were included in the content analysis. This resulted in 12 programs (see Table 1) covering five different genres (talk show, (comedy)-drama, reality show, game show, soap opera). From each program, the three most recent episodes including the LGB character or person were viewed and coded. Real-life people are listed with a number.

\section{Materials}

The content of the programs was analyzed with a coding scheme created for this study based on previous research. The programs were analyzed on eight variables (see Table 1): television program information, personal information about the character/person, traits, stereotypes, activities, sexual behavior, jokes, and relationships. The program information included: episode date or number, type of program, and name of the person/character. The personal information about the character included: gender, age, ethnicity, and sexual preference. We used the masculine and feminine traits of the previously mentioned OAT-AM (e.g. 'adventurous', 'dominant', 'charming' and 'gentle', Liben \& Bigler, 2002). The stereotypes were based on the studies of Madon (1997), Eliason et al. (1992), and a Dutch study that investigated stereotypes of LGBs amongst adolescents (Dankmeijer \& Schouten, 2013). An example of a stereotype about gay men is: "soft and/or high-pitched voice". An example of a stereotype about lesbians is: "has short hair". The coding for sexual behavior was based on Fisher et al. (2007). It measured whether there was any 'flirting', 'kissing', 'touching intimately', 'implied intercourse', 'visible intercourse' or 'other sexual behaviors'. Finally, we coded the activities of the character/person, whether any LGB related jokes were made and if so, by whom this joke was made, and whether the character/person had a relationship, if he/she was happy about it and whether he/she was monogamous or promiscuous.

\section{Procedure}

One coding scheme per LGB person in the program was filled in. If there were multiple LGB characters, the three characters that were most present were selected. For each program, the last three episodes which included the person of interest were selected to get a recent image of the portrayal of LGBs. Ten minutes of each episode were coded, starting from the moment the person of interest entered the episode. For some episodes, this meant that the first $10 \mathrm{~min}$ were coded as a whole, but for most episodes, different scenes with the person of interest were coded until the person was pictured for $10 \mathrm{~min}$ total. To determine the reliability a second independent coder analyzed $20 \%$ of the sample. The level of agreement between the two 


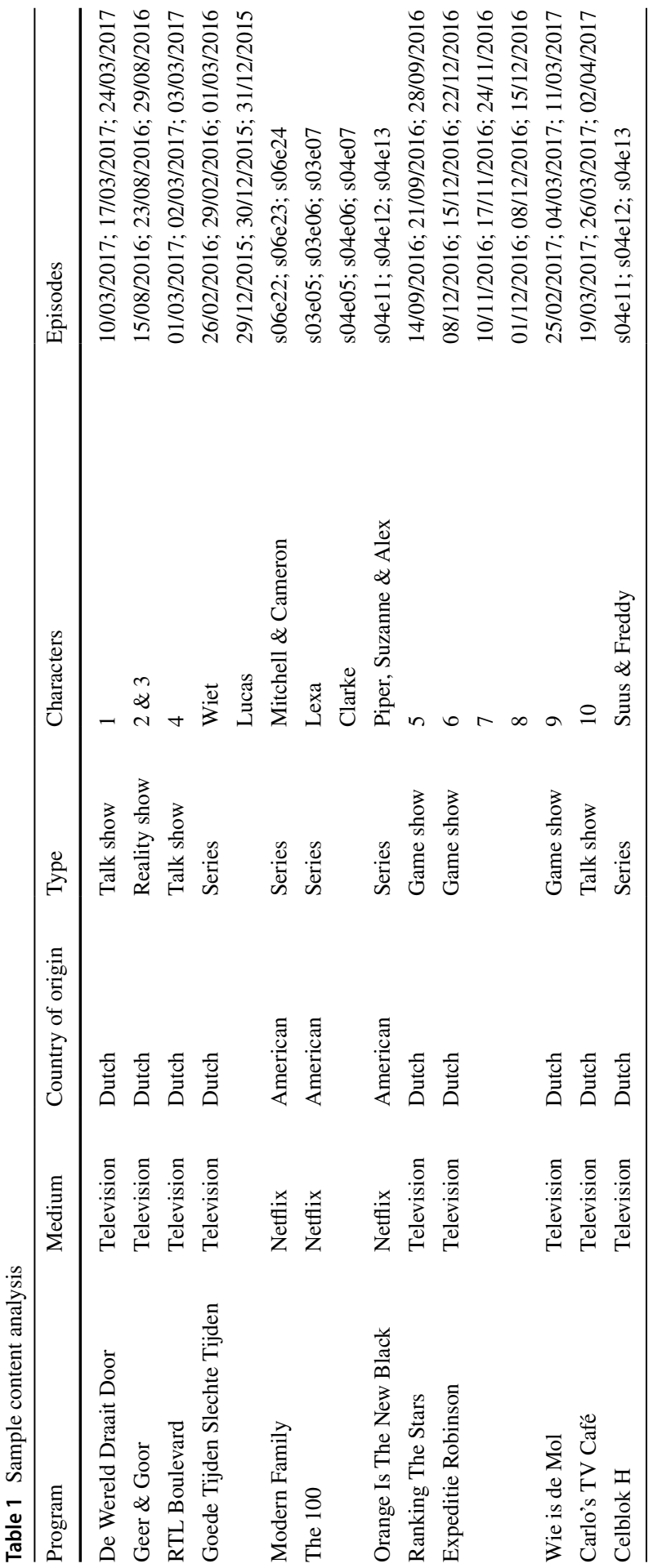


coders was moderate (Cohen's Kappa $=0.58$ ). An explanation for the moderate level of agreement is that several categories were similar, for example, 'sentimental' and 'emotional'.

To detect which of the analyzed programs stereotypically portrayed LGBs and which programs did not, the number of feminine and masculine characteristics and the number of stereotypes that were shown were determined. The other variables were analyzed to see if the characters/people formed a diverse group of LGBs and if they showed remarkable behavior that either contributes to or diminishes the stereotypes about LGBs.

\section{Results}

\section{Basic Statistics}

In total, twelve programs with 21 LGB characters/people were analyzed (10 women and 11 men). There were three game shows, three (comedy)-dramas, two talk shows, one reality show, one sitcom, and one soap opera. Nine of the programs were Dutch and three of the programs were produced in the US (Table 1). There was one Asian character and one African American character, the rest of the characters/people were Caucasian. Nine of the characters/people were young adults (aged between 20 and 35 years old), twelve were adults (aged between 36 and 65 years old) and none were seniors (65 years old or older). Eleven of the characters/people were gay men, four of them were bisexual women and six were lesbians.

\section{How Are Gay Men Represented?}

We first looked at whether gay men on television show masculine and feminine characteristics and found that there is a large variation in how gay men are represented on Dutch television. It depends to a great extent on the role they have in the program. Two gay men appeared as contestants in a game show and therefore scored relatively high on 'adventurous' and two others appeared as talk show hosts and therefore scored relatively high on 'confident' and 'charming'. Overall, six of the eleven analyzed men showed more than one feminine characteristic, with'talkative' as the most common one, followed by'helpful' and'complains a lot'. The other feminine characteristics that the six men showed were: 'emotional', 'irritable', 'try to look good', 'charming', 'gentle', 'affectionate', 'sentimental', 'loving' and 'cries a lot'. Programs in which gay men showed a high level of feminine characteristics were: "Geer and Goor", "Modern Family", and "Goede Tijden Slechte Tijden (GTST)" (see Table 2 for all programs, persons/characters, and the number of characteristics and stereotypes we found).

Next, we looked at whether gay men on television display gay stereotypes. We found that 7 out of the 11 men scored on one or multiple of these stereotypes. The most common stereotype that was present in the television programs was 'limp wrists and hand gestures' (shown by 6 out of $11 \mathrm{men}$ ), followed by 'a soft and/or 
Table 2 Characteristics and stereotypical behavior characters

\begin{tabular}{|c|c|c|c|c|}
\hline Program & Character & $\begin{array}{l}\text { Feminine } \\
\text { Character- } \\
\text { istics }\end{array}$ & $\begin{array}{l}\text { Masculine } \\
\text { Character- } \\
\text { istics }\end{array}$ & $\begin{array}{l}\text { Stereotypi- } \\
\text { cal behavior }\end{array}$ \\
\hline De Wereld Draait Door & 1 & 3 & 1 & 5 \\
\hline \multirow[t]{2}{*}{ Geer \& Goor } & 2 & 12 & 2 & 4 \\
\hline & 3 & 13 & 6 & 3 \\
\hline RTL Boulevard & 4 & 1 & 4 & 1 \\
\hline \multirow[t]{2}{*}{ Goede Tijden Slechte Tijden } & Wiet & 7 & 6 & 0 \\
\hline & Lucas & 9 & 7 & 7 \\
\hline \multirow[t]{2}{*}{ Modern Family } & Mitchell & 10 & 6 & 3 \\
\hline & Cameron & 10 & 2 & 5 \\
\hline \multirow[t]{2}{*}{ The 100} & Lexa & 1 & 13 & 0 \\
\hline & Clarke & 3 & 9 & 0 \\
\hline \multirow[t]{3}{*}{ Orange Is The New Black } & Piper & 3 & 7 & 1 \\
\hline & Suzanne & 8 & 7 & 2 \\
\hline & Alex & 10 & 2 & 1 \\
\hline Ranking the Stars & 5 & 3 & 8 & 3 \\
\hline \multirow[t]{3}{*}{ Expeditie Robinson } & 6 & 5 & 18 & 3 \\
\hline & 7 & 3 & 10 & 4 \\
\hline & 8 & 1 & 10 & 3 \\
\hline Wie is de Mol & 9 & 2 & 4 & 0 \\
\hline Carlo's TV Café & 10 & 7 & 9 & 0 \\
\hline \multirow[t]{2}{*}{ Celblok H } & Suus & 4 & 12 & 0 \\
\hline & Freddy & 0 & 8 & 0 \\
\hline
\end{tabular}

high pitched voice' (shown by 5 out of 11 men), and 'fashionable' (3 out of 11 men). The other two stereotypes (has a feminine walk and has a lot of female friends) were not present in our sample. Programs that showed a high number of stereotypes about gay men were: "GTST", "Modern Family" and "De Wereld Draait Door".

\section{How Are Lesbian and Bisexual Women Represented?}

The number of masculine and feminine characteristics shown by lesbian and bisexual women on television also varied depending on their role. Most of the women ( 8 out of 10) were depicted in a more masculine environment where they are more likely to show masculine characteristics (such as a prison, a deserted island, or a post-apocalyptic world). Nevertheless, all but one of the women showed at least one feminine characteristic in the episodes that were analyzed.

Nine women showed more than one masculine characteristic. The three most common characteristics were 'confidence', 'dominance', and'leadership'. The other masculine characteristics that the nine women displayed were: 'adventurous', 'independent', 'brave', 'aggressive', 'misbehaving', 'smart', 'strong', 'loud', 'competitive' 
and 'good in sports'. Programs where lesbian women showed a high level of masculine characteristics were: "Expeditie Robinson", "The 100", and "Celblok H".

Most of the women did not score on stereotypes that prevail about lesbian women. Only the three characters in Orange Is The New Black scored on the stereotype'wears wide clothing' because of their prison outfits and the contestants of "Expeditie Robinson" scored on the stereotype 'wears no makeup' because they are not allowed to bring makeup to the island.

\section{Jobs and Activities}

None of the male characters in the television series had jobs that are seen as more feminine and none of the female characters in the television series had jobs that are seen as more masculine. Most of the female characters did not have a job because they were in prison or were planning to make a trip around the world. The character that did have a job (Freddy in "Celblok H") was a legal assistant. Lexa and Clarke in "The 100" did not have a clear job, since they were surviving in a postapocalyptic world, but Lexa is the leader of her clan which puts her in a more masculine role. The male characters had gender-neutral or more masculine jobs: Lucas from "GTST" is an actor, Mitchell from "Modern Family" is a lawyer and Cameron from "Modern Family" is a physical education teacher. None of the male and female characters were part of any remarkable activities that were specifically feminine or masculine.

\section{Sexual Behavior}

As mentioned earlier, we followed Fisher et al. (2007) in coding sexual behavior and found that eight out of 33 (24.24\%) episodes of television series contained sexual behavior by LGBs. Three times a gay man was seen kissing (always Lucas in "GTST"). Six times a lesbian or bisexual woman showed sexual behavior $(3 \times$ kissing, $2 \times$ implied intercourse, $1 \times$ visible intercourse).

\section{Jokes}

Almost no LGB related jokes were made in our sample. Out of the 63 episodes, 4 episodes included an LGB related joke and all of these jokes were made by the LGB characters themselves.

\section{Relationships}

Only in a few of the television programs the relationship status of the person/characters was mentioned. The characters that did have a relationship seemed to have a happy relationship. The single characters seemed to be happy with being single. For a few characters, it was not clear whether they were single or not, because the relationship status was not a part of the episodes. These characters were scored as single and happy because they were not seen together with anyone and did not complain 
about being alone. For two of the characters (Lexa and Clarke from "The 100") it was not clear whether they were in a relationship or not, therefore the relationship status of the characters was scored as unclear. All of the relationships shown were monogamous. None of the characters (single or in a relationship) was promiscuous.

\section{Conclusion and Discussion}

We conclude that there are stereotypical representations of LGBs on Dutch television. Multiple programs in the sample show gay men with feminine characteristics and multiple programs include lesbian and bisexual women with masculine characteristics. Therefore these programs contribute to the stereotypes: 'lesbians are masculine' and 'gay men are feminine'. This effect is stronger for females than for males, because almost all lesbian and bisexual women were portrayed in a masculine acting way. For men, the representation was more diverse as not all of the gay men were portrayed in a feminine acting way. There were also several programs that did not contain stereotypical portrayals of gay men.

When looking at the specific categories we conclude that there is no indication that LGB characters have stereotypical jobs on television or that they are the subject of jokes. In our analysis we find no evidence for the notion that LGB characters/people are subjects of ridicule (Raley \& Lucas, 2006). We found sexual behavior in $24 \%$ of the programs. This is a lower percentage than a content analysis of sexual content in U.S. television programs found (35\%) (Kunkel et al., 2005) but comparable to other studies (Fisher et al., 2007; Rothmann, 2013). In line with earlier research, we found that lesbian and bisexual women were more likely to show sexual behavior than gay men (Ramirez, 2020). This provides some evidence for the notion that lesbian and bisexual women are portrayed in a more sexual way to please heterosexual male viewers. We further found that most LGBs were either in happy monogamous relationships or single, and not promiscuous. These results are not in line with the notion that LGB characters on television are unable to find love or promiscuous (Hart, 2000; Meyer, 2010).

Overall, our results are largely in line with those of previous studies based in the U.S. which also found that there are stereotypical representations of LGBs on television (Hart, 2000; Raley \& Lucas, 2006; Rothmann, 2013). However, the representation on Dutch television seems to be less stereotypical, because there are some gay men that are talk show host that 'just happen to be gay'. Most of the lesbian and bisexual characters looked feminine (they did not score on the stereotypes 'wears no makeup', 'wears wide clothing' and 'has short hair'), but in their behavior, they showed masculine characteristics. These findings match with the findings of previous research (Ciasullo, 2001; Diamond, 2005; Farr \& Degroult, 2008; Jenkins, 2005; Meyer, 2010) in which lesbian and bisexual women were also portrayed as feminine looking. These portrayals adhere to existing gender norms, making lesbians on television more acceptable for heterosexual male viewers. Farr and Degroult (2008) also found that lesbian characters show masculine behavior and explain it as a feature that is recognizable for lesbians in real life, while their feminine appearance is aimed to please heterosexual male 
viewers. The same phenomenon can be found in our sample, but it has to be noted that the masculine behavior displayed by the women in our sample mostly arose from the role they had in the series. Four women in our sample were prisoners. This is worrisome because it might create a new negative stereotype about lesbian and bisexual women.

A diverse representation also means that LGBs of all ethnicities and ages and bisexuals of both genders are represented. Research about role models stresses the importance of a diverse representation that causes recognition amongst LGBs (Gomillion \& Giuliano, 2011; Ochman, 1996; Wohlford et al., 2004). In our sample, there was a relatively diverse representation of age, although there were no seniors represented. However, there were no bisexual men present in the sample and almost all of the characters/people that were analyzed were Caucasian (90.48\%). In the Netherlands, $22 \%$ of the inhabitants have an immigrant background. The largest groups of people with a non-Caucasian background in The Netherlands are the Turkish, the Moroccan, the Indonesian, and the Surinamese (CBS, 2016). Only one of these ethnicities was represented in the sample (Number 8 is Indonesian). The fact that almost all LGBs were Caucasian corresponds with an analysis of Flemish television fiction in which $97 \%$ of the character were Caucasian (Vanlee et al., 2020). For more recognition amongst non-Caucasian LGBs, more non-Caucasian LGBs should be on television.

Overall, the representation of LGBs in our sample of programs that were on Dutch television in 2017 is less stereotypical than in older studies from other countries (Hart, 2000; Raley \& Lucas, 2006). While the behavior and/or appearances of some individuals was somewhat stereotypical, most of the LGBs were not found engaging in stereotypical activities. They also did not have stereotypical jobs and were not the subject of jokes and ridicule.

Besides answering the research question, the goal of this study was to make a selection of programs with high levels and low levels of stereotypical representations of LGBs for the second study. For gay men, there were three programs with relatively high levels of stereotypical representations: Modern Family, "Geer en Goor" and "GTST" and three programs with relatively low levels of stereotypical representations: "RTL Boulevard", "Carlo's TV Café" and "Wie Is De Mol". For lesbian and bisexual women there were four programs with high levels of stereotypical representations: "Expeditie Robinson", "Orange Is The New Black", "Celblok H" and "The 100" but there was no program which could be categorized as low on stereotypical representations. The character in "GTST" did show some masculine characteristics, but not a lot, and therefore does not fall into either category. 


\section{Study 2}

\section{Method}

With an online survey, we measured to what extent people are exposed to the programs from Study 1 (and television in general) and how this relates to their perceptions of and attitudes towards LGBs.

\section{Sample}

There were 272 participants in our convenience sample ( 85 male, 187 female). The participants were recruited via the participant pool and through social media, by sending out a link to the survey. The survey started with several questions about the participants' demographics. The participants had a mean age of 26.62 years $(\mathrm{SD}=11.33)$. The majority $(93.80 \%)$ identified as heterosexual, $1.50 \%$ as lesbian, $3.70 \%$ as bisexual, and $0.70 \%$ as gay. In the analyses, the categories lesbian, bisexual, and gay were merged into one non-heterosexual category. The majority had a higher level of education (88.6\%) (medium 6.3\%, lower 5.1\%). Ethnicity was distributed as follows: $0.70 \%$ African, 2.20\% Asian, 89.30\% Caucasian, 0.70\% Hindu, 0.40\% Latin, $0.40 \%$ North African, $0.70 \%$ Turkish, and $11.00 \%$ selected the option 'other'. In the analysis, the groups African, Asian, Hindu, Latin, North African, Turkish, and 'other' were merged to create a dichotomous variable (Caucasian/nonCaucasian). The majority identified as 'not religious' (72.40\%) (23.90\% Christian, $1.10 \%$ Muslim, $2.20 \%$ 'other'). The categories Christian, Muslim, and 'other' were merged to create a dichotomous variable (religious/non-religious).

\section{Scales}

Using the same stereotypes as in Study 1, we measured to what extent participants agree with the stereotypes on a 5-point-scale. The scales (homosexual men: $\alpha=0.83$; lesbian women: $\alpha=0.75$ ) had a high internal reliability. A higher score indicates a more stereotypical view. On average participants had a somewhat stereotypical view of gay men and lesbians. The means and standards deviations of all variables can be found in Table 3.

The extent to which participants ascribe feminine and masculine characteristics to LGBs was measured on a 5-point scale. The 37 characteristics were based on the traits from the OAT-AM by Liben and Bigler (2002) and were similar to the characteristics used in the coding scheme of the first study. A higher score indicated that the participants found it more likely that LGBs showed masculine and feminine characteristics. The scales for masculine characteristics $(\alpha=0.87)$ and feminine characteristics $(\alpha=0.92)$ of gay men had a high reliability, as the scales for masculine characteristics $(\alpha=0.89)$ and feminine characteristics $(\alpha=0.90)$ of lesbians.

To measure participants' attitudes towards gay men and women they indicated the extent to which they agreed with twelve statements about homosexuality based on Kuyper (2015, e.g. 'I find it offensive when two women kiss in public'). The 


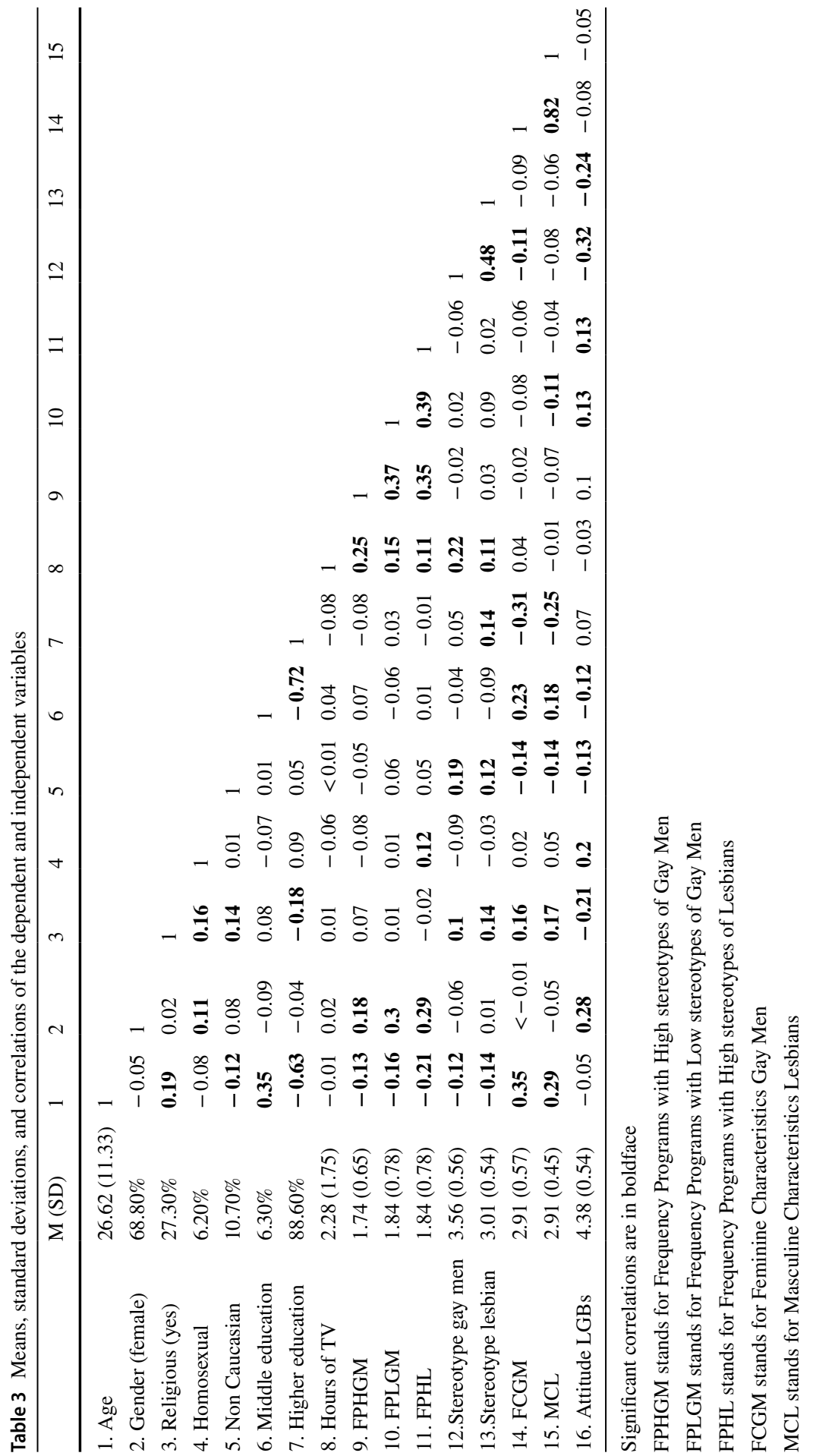


items were measured on a 5-point scale (from 'highly agree' to 'highly disagree') with the extra option 'never thought about it'. A higher score indicated a more positive attitude towards homosexuality. The scale had a high reliability $(\alpha=0.85)$. The participants on average had a positive attitude towards homosexuality.

Finally, the survey measured how often the participants watched the programs from Study 1 [on a scale from 1 (never) to 5 (always)]. For every participant, it was calculated how often they watched programs with a high level of stereotypical representations of gay men, programs with a low level of stereotypical representations of gay men, and programs with a high level of stereotypical representations of lesbian women. We also measured how many hours the participants watched television or streaming services like Netflix on weekdays and weekends.

\section{Results}

\section{Media Use and Stereotypical Views}

To investigate our first hypothesis we conducted four regression analyses about the relationship between watching television and the following dependent variables: stereotypical view of gay men, stereotypical view of lesbian women, feminine characteristics of gay men, and masculine characteristics of lesbian women. All models included age, gender, sexual preference, religion, ethnicity, and level of education as control variables in the first block and added variables about media consumption in the second block: hours of television watched per day, frequency of watching television programs with a high level of stereotypical representations of gay men, frequency of watching television programs with a low level of stereotypical representation of gay men, and frequency of watching television programs with a high level of stereotypical representations of lesbians. The means, standard deviations, and correlations of the dependent and independent variables can be found in Table 3. No unexpected correlations were found. All model statistics and confidence intervals for the coefficients can be found in Table 4. In all of the models, the residuals were not normally distributed, so we based our conclusions about significance on the bootstrapped confidence intervals.

\section{Stereotypical View of Gay Men}

There was significant skewness $(z$-score $=2.95)$ in the distribution of the residuals. The model of the first block was significant $\left(R_{\text {adj }}^{2}=0.04, F_{\text {change }}(7,255)=2.54\right.$, $p=0.015)$. Participants who were older had a less stereotypical view of gay men, and participants who were not Caucasian had a more stereotypical view of gay men. The addition of the variables about media consumption in the second block resulted in a significantly better model $\left(R_{\mathrm{adj}}^{2}=0.08, F_{\text {change }}(3,252)=4.69, p=0.003\right)$. Besides age and ethnicity, hours of television watched per day was also significantly 


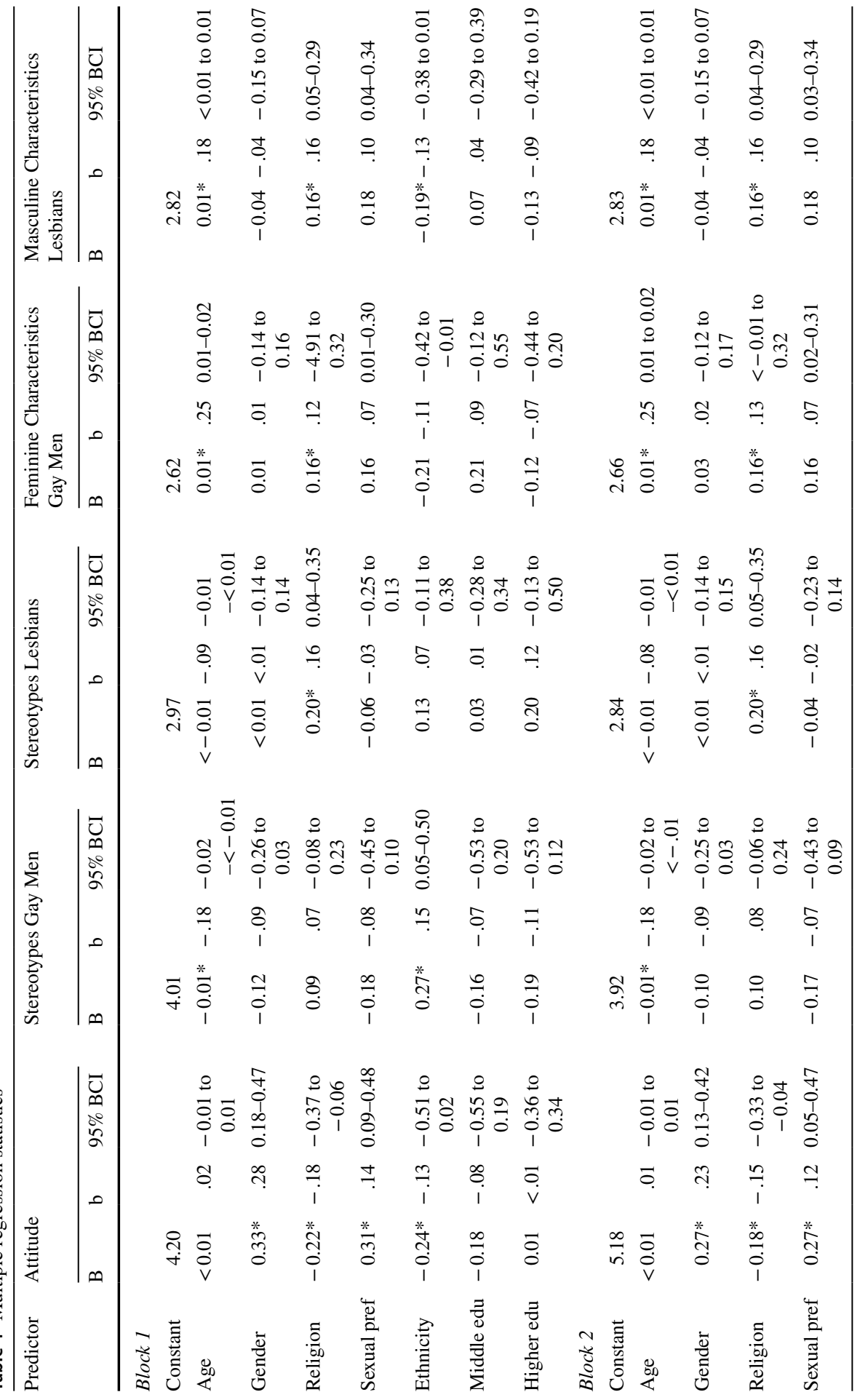




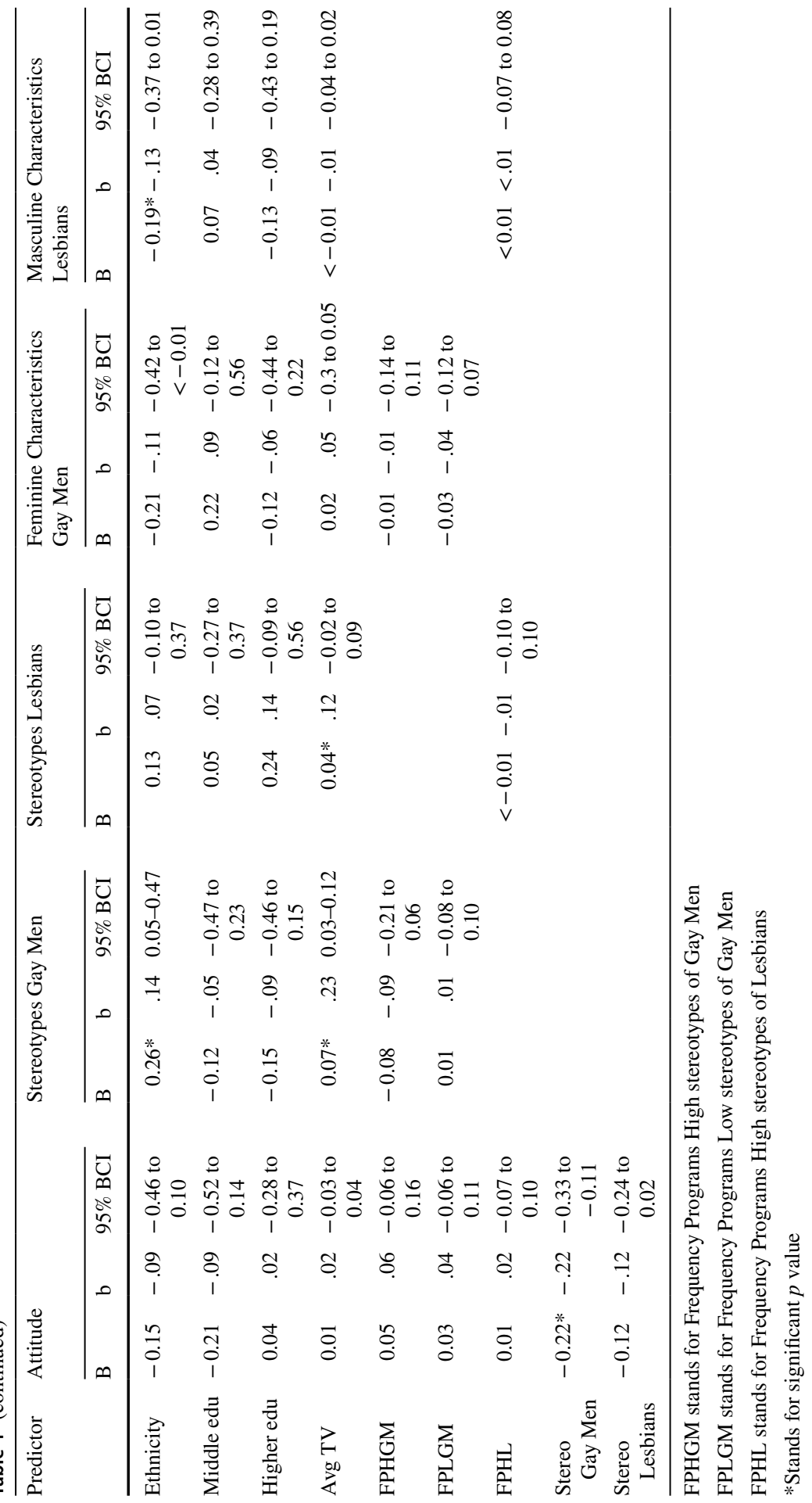


related to the stereotypical view in that participants who watch more television have a more stereotypical view of gay men.

\section{Stereotypical View of Lesbians}

There was significant kurtosis $(z$-score $=4.60)$ in the distribution of the residuals. The model of the first block was significant $\left(R_{\text {adj }}^{2}=0.03, F_{\text {change }}(7,255)=2.19\right.$, $p=0.035)$. Participants who were religious had a more stereotypical view of lesbians. The addition of the media consumption variables did not result in a significantly better model $\left(R_{\text {adj }}^{2}=0.04, F_{\text {change }}(2,253)=1.88, p=0.154\right)$.

\section{Feminine Characteristics of Gay Men}

Besides analyzing whether people ascribe explicit stereotypes to LGBs, we also measured whether they ascribe feminine characteristics to gay men to see if the stereotype 'gay men are feminine' applies and whether this stereotype is shaped by television. There was significant kurtosis $(z$-score $=3.67)$ in the distribution of the residuals. The model of the first block was significant $\left(R_{\text {adj }}^{2}=0.15, F_{\text {change }}(7\right.$, $255)=7.43, p<0.001)$. Participants who were older, Caucasian, and who were not heterosexual ascribed more feminine characteristics to gay men. The addition of the variables about media consumption in the second block did not result in a significantly better model $\left(R_{\text {adj }}^{2}=0.14, F_{\text {change }}(3,252)=0.32, p=0.808\right)$.

\section{Masculine Characteristics of Lesbians}

There was significant kurtosis $(\mathrm{z}$-score $=15.05)$ in the distribution of the residuals. The model of the first block was significant $\left(R_{\text {adj }}^{2}=0.11, F_{\text {change }}\right.$ (7, $255)=5.50, p<0.001)$. Participants who were older, who were religious, and who were not heterosexual ascribed more masculine characteristics to lesbians. The addition of the variables about media consumption in the second block did not result in a significantly better model $\left(\mathrm{R}_{\text {adj }}{ }^{2}=0.10, F_{\text {change }}(2,253)=0.02\right.$, $p=0.981)$.

From these four analyses, we can conclude that our first hypothesis (people who watch programs with stereotypical portrayals of LGBs have a more stereotypical image of LGBs) is not supported. However, we do find that people who watch more television in general do have a more stereotypical view of gay men.

\section{Media Use and Attitudes}

To investigate our second hypothesis (stereotypical representations of LGBs on Dutch television are positively related to people's attitudes towards LGBs), we conducted a regression model with the attitude towards LGBs as dependent variable 
and the same predictors as before, plus the variables 'stereotypes of gay men' and 'stereotypes of lesbians'.

There was significant skewness and kurtosis (z-score skewness $=-5.33$, z-score kurtosis $=3.74$ ) in the distribution of the residuals. The model of the first block was significant $\left(R_{\text {adj }}^{2}=0.15, F_{\text {change }}(7,255)=7.52, p<0.001\right)$. Participants who were male, heterosexual, religious, and not Caucasian had a more negative attitude towards LGBs. The addition of the variables about media consumption and stereotypes resulted in a significantly better model $\left(R_{\text {adj }}^{2}=0.22, F_{\text {change }}(6,249)=4.99\right.$, $p<0.001)$. Besides gender, sexuality, and religion, a stereotypical view of gay men was also significant. Specifically, participants who have a more stereotypical view of gay men have a more negative attitude towards LGBs. The effect of ethnicity was no longer significant.

Our second hypothesis was not confirmed. Watching programs with stereotypical representations of LGBs was not positively related to people's attitudes towards LGBs. However, we found that people who have a more stereotypical view of gay men have a more negative attitude towards LGBs.

\section{Mediation Analysis}

Because the hours of television watched per day was significantly related to the level of stereotypes about gay men and the level of stereotypes about gay men was significantly related to the attitude towards LGBs in the previous analyses, a mediation analysis using PROCESS (Hayes, 2013) was conducted. There was no total effect in this model, but that can happen if different effects cancel each other out (Hayes, 2009). There was no significant direct effect between the hours of television watched per day and the attitude towards LGBs $(b=0.01, S E=0.02, t=0.69, p=0.491$, BCI $[-0.02 ; 0.05])$. There was, however, a significant indirect effect through stereotypes about gay men $(b=-0.02, S E=0.01,95 \%$ BCI $[-0.04 ;-0.01]$. This indicates that there is a relationship between the hours of television watched per day and the attitude towards LGBs through the mediating variable stereotypes about gay men.

\section{Conclusion and Discussion}

The first hypothesis 'people who view more programs with stereotypical portrayals of LGBs on television have a more stereotypical view of LGBs in reality' was not confirmed. People who watch programs with high levels of stereotypical representations of LGBs do not have a more stereotypical view of LGBs. The concept of stereotyped identification (Mclaughlin \& Rodriguez, 2017) and cultivation theory in general (Morgan et al., 2009) predict that stereotypical representations will reinforce stereotypes by making them more available. This was not the case here.

We did find, however, that people who watch more television in general do have a more stereotypical view of gay men. Watching television is not the only significant predictor of how stereotypical gay men are viewed. Age and ethnicity also had a significant influence. People who are younger and not-Caucasian have a more 
stereotypical view of gay men. These findings are in line with previous research showing that people with an immigrant background or who are young have a more negative attitude towards LGBs (Kuyper, 2015; de Roos et al., 2014). This can be explained by cultivation theory that states that people who have less experience with something (for example because in their culture LGBs are less accepted and therefore less visible) are more influenced by television (Morgan et al., 2009).

The level of feminine characteristics ascribed to gay men was not related to the time spent watching television. However, age and sexual preference did have a significant influence on the level of feminine characteristics ascribed to gay men, people who are older and people who are not heterosexual ascribe more feminine characteristics to gay men. Previous research also found that LGBs were more aware of the stereotypes that prevail about them than heterosexual people are (Dankmeijer \& Schouten, 2013). Because there was only a small number of nonheterosexual participants (6.2\% of the sample) this result has to be interpreted cautiously. An explanation for the effect of age might be that people who are older grew up with stricter beliefs about gender norms. Because gay men are similar to heterosexual women, in the sense that they are attracted to men, they are expected to also show other feminine characteristics (Blashill \& Powlishta, 2009a).

Watching television did not have a significant relation with how stereotypical lesbians are viewed. This could be explained by the fact that the lesbian and bisexual women in the programs in the questionnaire were not represented stereotypically (with short hair or wide clothing), they had a feminine appearance. The only significant predictor of this view was religion, religious people had a more stereotypical view of lesbians. The level of masculine characteristics ascribed to lesbians was also not influenced by television. However, participants who were older, who were religious, and who were not heterosexual ascribed more masculine characteristics to lesbians. These findings connect to the findings about gay men.

The second hypothesis 'People who view more programs with stereotypical representations of LGBs on Dutch television have more positive attitudes towards LGBs' was also not confirmed. No direct relationship between watching television and the attitude towards LGBs was found. This could be due to a ceiling effect because the attitude of the participants towards LGBs was very positive. However, we did find that people who have higher levels of stereotypes about gay men have a more negative attitude about LGBs. This can be explained by the fact that stereotypes defying gender norms (men are supposed to be masculine) can lead to a more negative attitude (Blashill \& Powlishta, 2009b). Besides that, gender, religion, ethnicity, and sexuality also were significant predictors of attitude towards LGBs. Participants who were male, heterosexual, religious, and not Caucasian had a more negative attitude towards LGBs.

The mediation analysis revealed an indirect effect of watching television on the attitude towards LGBs. The more people watch television, the more stereotypical their view of gay men is, and the more negative their attitude towards LGBs is. We can, therefore, conclude that watching television is related to the attitude towards LGBs via a stereotypical view. However, given the cross-sectional nature of our study, we cannot draw any conclusions about the direction of the effect. 
The sample consisted mostly of Caucasian, non-religious, heterosexual people. The effects found on ethnicity, religion, and sexual preference, therefore, might not be representative of the population at large. Future research should include more participants who are religious, homosexual, and/or non-Caucasian to investigate if these findings replicate. Also keep in mind that the purpose of this study was not to find a sole predictor of attitudes towards or stereotypes about LGBs, but to see whether television contributes as a predictor of stereotypes about and attitudes towards LGBs. The effect sizes of the significant predictors were small to medium (minimum $R^{2}=0.03$, maximum $R^{2}=0.28$ ). As always with correlational research, it has to be taken into account that there could be other variables that influence the relationships or that the relationships could be reversed.

\section{General Discussion}

The goal of the current project was to investigate whether there are stereotypical representations of LGBs on Dutch television and how these are related to people's view of and attitude towards LGBs is. To accomplish this goal we used a combination of qualitative and quantitative research. The analysis of programs featuring LGB people and characters shows that there are stereotypical representations of LGBs on Dutch television. The survey revealed that people who are frequent viewers of these programs with stereotypical portrayals do not have a different attitude towards LGBs than people who do not watch these programs frequently. It also revealed that people do have stereotypes about LGBs and that the level of the stereotypes about gay men is associated with watching television. The more people watch television the higher their level of stereotypes about gay men is. The higher the level of people's stereotypes about gay men, the more negative their attitude towards LGBs is.

Our findings are in line with cultivation theory research which states that more exposure to negative stereotypes is related to a more negative attitude towards the phenomenon in general (Dixon, 2008; Morgan et al., 2009). We did not find this link for the specific programs with high levels of stereotypical representation of gay men, but we did find it for watching television in general. Many of the gay men in the programs that had high levels of stereotypes of gay men are famous in The Netherlands and created many television shows before the specific programs that were analyzed. They also regularly appear in other shows. Besides that, news items that feature LGBs were not included in the content analysis. Further research could investigate the influence of news items on the attitude towards LGBs to get a fuller understanding of how these attitudes are influenced by the media.

We found no evidence for the concept of stereotyped identification, which states that stereotypical portrayals of LGBs is related to more positive attitudes (McLaughlin \& Rodriguez, 2017). Instead, we found that stereotypical views of gay men were linked to a more negative attitude towards LGBs. Therefore, this study implicates that the stereotypical portrayal of LGBs on television should be reduced and/or be more nuanced. Even if reducing the stereotypical portrayal of gay men on television could only slightly reduce negative attitudes towards LGBs 
this would be an improvement, given the negative consequences of negative attitudes towards LGBs (De Graaf et al., 2006).

Besides influencing heterosexuals, how LGBs are portrayed on television also influences LGBs. As was stressed in the introduction, visibility and diverse representations of LGBs are important (Gomillion and Giuliano, 2011). We found that gay men are both represented stereotypically and not stereotypically. This is a good development because gay men in real life also vary in how stereotypical they look and act. This relatively balanced representation of gay men was not found in research about the representation of gay men on television before (Hart, 2000; Raley \& Lucas, 2006; Rothmann, 2013).

The representation of lesbians and bisexual women, however, was less diverse. They were mainly represented with feminine looks. Representing lesbian and bisexual women with a feminine appearance might lead to more acceptance because it makes them less controversial. However, it is important to represent lesbian and bisexual women diversely (more masculine looking and/or more feminine acting, besides feminine looking and masculine acting). More real-life lesbian and bisexual women on television (for example as hosts of talk shows) instead of only characters in series will create a more diverse and more realistic representation of lesbian and bisexual women. Of course, not all of the programs on Dutch television including lesbian and bisexual women were analyzed. Nevertheless, programs that were most known for including lesbian and bisexual women were selected. While most researchers selected the programs they analyzed themselves (Ciasullo, 2001; Farr \& Degroult, 2008; Hart, 2000; Jenkins, 2005; Raley \& Lucas, 2006; Rothmann, 2013; Vanlee et al., 2018), we used a pilot study with lay people to select programs to assure the sample represents programs and people that Dutch people know about. To our knowledge, there are no other current Dutch television series including lesbian and bisexual women.

For some stereotypes found in previous research more extensive analyses are needed. Previous research found that LGBs in television series often have unhappy love lives (Hart, 2000). They are either unable to find a partner or are promiscuous when they have a relationship. This stereotype could communicate the message that LGBs are unable to have happy and successful relationships. There was no indication that this stereotype was present in the episodes that were analyzed in this study. To fully analyze this stereotype more than three episodes would need to be included in the analysis. In an analysis of the full storylines around LGB characters in Flemish productions, Vanlee and colleagues (2018) found that the narratives regarding romantic interests and partners were presented in such a way that their sexuality was not the main focus or something that needed to discussed, thereby normalizing the love stories of LGB. In future studies, a comparison between LGB characters and heterosexual characters could be made to analyze whether they are portrayed differently.

This study found that the share of LGB characters/people on television with nonCaucasian ethnicities is lower than the actual share of LGBs with non-Caucasian ethnicities in The Netherlands. Besides that, bisexual men were not present in the sample. This indicates that bisexual men are not represented very well on television. 
A more diverse and realistic representation of LGBs will influence the psychological well-being of LGBs positively (Gomillion and Giuliano, 2011).

There are open questions this study cannot answer. For example: to what extent are the stereotypes that exist about LGB justified and are the stereotypes exaggerated on television? So for example, do lesbians indeed more often have short hair than heterosexual women and do lesbians on television more often have short hair than lesbians in reality? In our sample, only one of the ten female characters/people had short hair. So for this particular stereotype there does not seem to be an exaggeration, but there are many more that would need to be investigated. Future studies should look into this. Based on that information, TV and movie producers can be more careful in how they represent LGB, to prevent any exaggeration of stereotypes.

Positive representations of LGBs on television can serve as role models for LGBs in real life, providing a source of comfort, pride, and recognition. As noted in the beginning, one participant of Gomillion and Giuliano (2011) wished for: "'normal people with normal jobs who just happen to be gay'. Our study shows that, in the Netherlands, several gay men on television meet this wish. However, the representation of lesbians and bisexuals lacks accuracy and diversity.

Authors' Contributions Conception or design of the work: MM, Data collection: MM, Data analysis and interpretation: MM \& MP, Drafting the article: MM, Critical revision of the article: MM \& MP, Final approval of the version to be published: MP.

Funding No funding was received for this research.

Availability of Data and Materials The data and materials are available upon request.

Code Availability Not applicable.

\section{Declarations}

Conflict of interest There are no conflict of interest or competing interests.

Ethical Approval This research was conducted following the rules and regulations of the code of conduct for scientific practice (General Board of the Association of Universities (2004). The Netherlands code of conduct for scientific practice. Available: http://www.uu.nl/university/utrecht/EN/profileandmissi onstatement/Documents/The_Netherlands_Code_of_Conduct_for_Scientific_Practice.pdf.) and the code of conduct for personal data in scientific research (Association of Universities (2005). Gedragscode voor gebruik van persoonsgegevens in wetenschappelijk onderzoek. Available: http://www.vsnu.nl/files/docum enten/Domeinen/Accountability/Codes/Gedragscode\%20persoonsgegevens.pdf).

Consent to Participate All participants gave their informed consent prior to participating in this study.

Open Access This article is licensed under a Creative Commons Attribution 4.0 International License, which permits use, sharing, adaptation, distribution and reproduction in any medium or format, as long as you give appropriate credit to the original author(s) and the source, provide a link to the Creative Commons licence, and indicate if changes were made. The images or other third party material in this article are included in the article's Creative Commons licence, unless indicated otherwise in a credit line to the material. If material is not included in the article's Creative Commons licence and your intended use is not permitted by statutory regulation or exceeds the permitted use, you will need to obtain permission directly from the copyright holder. To view a copy of this licence, visit http://creativecommons.org/licenses/by/4.0/. 


\section{References}

Blashill, A. J., \& Powlishta, K. K. (2009a). Gay stereotypes: The use of sexual orientation as cue for gender-related attributes. Sex Roles, 61, 783-793.

Blashill, A. J., \& Powlishta, K. K. (2009b). The impact of sexual orientation and gender role on evaluations of men. Psychology of Men \& Masculinity, 10, 160-173.

Brown, J. D., Halpern, C. T., \& L'Engle, K. L. (2005). Mass media as a sexual super peer for early maturing girls. Journal of Adolescent Health, 36, 420-427.

Bonds-Raacke, J., Cady, E., Schlegel, R., Harris, R., \& Firebaugh, L. (2007). Remembering gay/lesbian media characters: Can Ellen and Will improve attitudes toward homosexuals? Journal of Homosexuality, 53, 19-34.

Calzo, J. P., \& Ward, L. M. (2009). Media exposure and viewers' attitudes toward homosexuality: Evidence for mainstreaming or resonance? Journal of Broadcasting \& Electronic Media, 53, 280-299.

CBS. (2016). Bevolking naar migratieachtergrond. https://www.cbs.nl/nl-nl/achtergrond/2016/47/bevol king-naar-migratieachtergrond.

Ciasullo, A. M. (2001). Making her (in)visible: Cultural representations of lesbianism and the lesbian body in the 1990s. Feminist Studies, 27, 577-608.

Dankmeijer, P. \& Schouten, M. (2013). Mietjes moeten we niet. Stereotypen over gender en seksuele diversiteit onder jongeren en homo's, lesbiennes en biseksuelen in Nederland. EduDivers. http:// www.edudivers.nl/doc/onderzoek/Mietjes\%20moeten\%20we\%20niet.pdf

De Graaf, R., Sandfort, T. G., \& ten Have, M. (2006). Suicidality and sexual orientation: Differences between men and women in a general population-based sample from the Netherlands. Archives of Sexual Behavior, 35, 253-262.

de Roos, S., Kuyper, L., \& Iedema, J. (2014). "Ik vind het vies als twee jongens met elkaar zoenen." Houding ten opzichte van lesbische, homoseksuele en biseksuele jongeren onder Nederlandse scholieren. Tijdschrift voor Seksuologie, 38(2), 58-67.

Diamond, L. (2005). 'I'm Straight But I Kissed a Girl': The trouble with American media representations of female-female sexuality. Feminism and Psychology, 15, 104-110.

Dixon, T. L. (2008). Network news and racial beliefs: Exploring the connection between national television news exposure and stereotypical perceptions of African Americans. Journal of Communication, 58, 321-337.

Eliason, M., Donelan, C., \& Randall, C. (1992). Lesbian stereotypes. Health Care for Women International, 13, 131-144.

Emons, P., Wester, F., \& Scheepers, P. (2010). "He Works Outside the Home; She Drinks Coffee and Does the Dishes" Gender Roles in Fiction Programs on Dutch Television. Journal of Broadcasting \& Electronic Media, 54(1), 40-53.

Farr, D., \& Degroult, N. (2008). Understand the queer world of the L-esbian body: Using queer as folk and the $\mathrm{L}$ word to address the construction of the Lesbian body. Journal of Lesbian Studies, 12, 423-434.

Fisher, D. A., Hill, D. L., Grube, J. W., \& Gruber, E. L. (2007). Gay, lesbian, and bisexual content on television: A quantitative analysis across two seasons. Journal of Homosexuality, 52, 167-188.

Fouts, G., \& Inch, R. (2005). Homosexuality in TV situation comedies: Characters and verbal comments. Journal of Homosexuality, 49, 35-45.

Gerhards, J. (2010). Non-discrimination towards homosexuality: The European Union's policy and citizens' attitudes towards homosexuality in 27 European countries. International Sociology, 25, 5-28.

Gomillion, S. C., \& Giuliano, T. A. (2011). The influence of media role models on gay, lesbian, and bisexual identity. Journal of Homosexuality, 58, 330-354.

Hayes, A. F. (2009). Beyond Baron and Kenny: Statistical mediation analysis in the new millenium. Communication Monographs, 76, 408-420.

Hayes, A. F. (2013). Introduction to mediation, moderation and conditional process analysis: A regression-based approach. The Guilford Press.

Hart, K. P. R. (2000). Representing gay men on American television. The Journal of Men's Studies, 9, 59-79.

Jenkins, T. (2005). Potential lesbians at two o' clock': The heterosexualisation of lesbianism in the recent teen film. Journal of Popular Culture, 38, 491-504.

Johnson, H. J. (2016). Bisexuality, mental health, and media representation. Journal of Bisexuality, 16, $378-396$. 
Keuzenkamp, S., Kooiman, N., \& van Lisdonk, J. (2012). Niet te ver uit de kast. Ervaringen van homoen biseksuelen in Nederland. Sociaal en Cultureel Planbureau. https://www.scp.nl/Publicaties/Alle_ publicaties/Publicaties_2012/Niet_te_ver_uit_de_kast

Kite, M. E., \& Deaux, K. (1987). Gender belief systems: Homosexuality and the implicit inversion theory. Psychology of Women Quarterly, 11, 83-96.

Kuyper, L. (2015). Wel trouwen, niet zoenen. De houding van de Nederlandse bevolking tegenover lesbische, homoseksuele, biseksuele en transgender personen 2015. Sociaal en Cultureel planbureau. http://platform-keelbos.org/sites/default/files/Wel\%20trouwen,\%20niet\%20zoenen_web.pdf

Lee, T. T., \& Hicks, G. R. (2011). An analysis of factors affecting attitudes toward same-sex Marriage: Do the Media Matter? Journal of Homosexuality, 58, 1391-1408.

Liben, L. S., \& Bigler, R. S. (2002). The developmental course of gender differentiation: Conceptualizing, measuring, and evaluating constructs and pathways. Monographs of the Society for Research in Child Development, 67, 1-187.

Lin, K., Button, D. M., Su, M., \& Chen, S. (2016). Chinese college students' attitudes toward homosexuality: exploring the effects of traditional culture and modernizing factors. Sexuality Research and Social Policy, 13(2), 158-172.

Kunkel, D., Eyal, K., Finnerty, K., Biely, E., \& Donnerstein, E. (2005). Sex on TV 4 2005: A Kaiser Family Foundation report. The Henry J. Kaiser Foundation. https://kaiserfamilyfoundation.files.wordp ress.com/2013/01/sex-on-tv-4-full-report.pdf

Madon, S. (1997). What do people believe about gay males? A study of stereotype content and strength. Sex Roles, 37, 663-685.

Mclaughlin, B., \& Rodriguez, N. S. (2017). Identifying with a stereotype: The divergent effects of exposure to homosexual television characters. Journal of Homosexuality, 64, 1-18.

Meyer, M. D. E. (2010). Representing bisexuality on television: The case for intersectional hybrids. Journal of Bisexuality, 10, 366-387.

Morgan, M., Shanahan, J., \& Signorielli, N. (2009). Growing up with television: Cultivation processes. In J. Bryant \& M. B. Oliver (Eds.), Media effects: Advances in theory and research (3rd ed.). Routledge.

Ochman, J. M. (1996). The effects of nongender-role stereotyped, same-sex role models in storybooks on the self-esteem of children in grade three. Sex Roles, 35, 711-735.

Parker, K. M., Sadika, B., Sameen, D. E., Morrison, T. G., \& Morrison, M. A. (2020). Humanizing lesbian characters on television: Exploring their characterization and interpersonal relationships. Journal of Lesbian Studies, 24(4), 395-413.

Raley, A. B., \& Lucas, J. L. (2006). Stereotype or success? Prime-time television's portrayals of gay male, lesbian, and bisexual characters. Journal of Homosexuality, 51, 19-38.

Ramírez, R. (2020). Simplified identities: Four 'types' of gays and lesbians on Chilean telenovelas. Sexualities, 23(8), 1480-1498. https://doi.org/10.1177/1363460720902711

Riggle, E. D., Ellis, A. L., \& Crawford, A. M. (1996). The impact of "media contact" on attitudes toward gay men. Journal of Homosexuality, 31(3), 55-69.

Rothmann, J. (2013). Send in the (gay) clowns': Will \& Grace and Modern Family as' sensibly queer. Acta Academica, 45, 40-83.

Sanz López, J. M. (2017). Shaping LGBTQ identities: Western media representations and LGBTQ people's perceptions in rural Spain. Journal of Homosexuality, 65, 1817-1837.

Van den Bulck, J. (2004). Research note: The relationship between television fiction and fear of crime. European Journal of Communication, 19, 239-248.

Vanlee, F., Dhaenens, F., \& Van Bauwel, S. (2018). Understanding queer normality: LGBT+ representations in millennial Flemish television fiction. Television \& New Media, 19(7), 610-625.

Vanlee, F., Dhaenens, F., \& Van Bauwel, S. (2020). LGBT+ televisibility in Flanders: The presence of sexual and gender diversity in Flemish television fiction (2001-2016). Digest. Journal of Diversity and Gender Studies, 7(1), 6-22.

Wohlford, K. E., Lochman, J. E., \& Barry, T. D. (2004). The relation between chosen role models and the self-esteem of men and women. Sex Roles, 50, 575-582.

Publisher's Note Springer Nature remains neutral with regard to jurisdictional claims in published maps and institutional affiliations. 